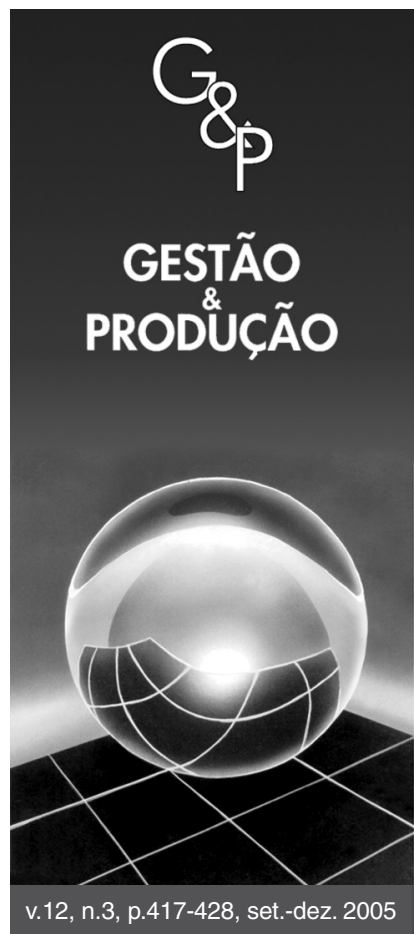

\title{
ESTRATÉGIA DE PRODUÇÃO EM EMPRESAS COM LINHAS DE PRODUTOS DIFERENCIADAS: UM ESTUDO DE CASO EM UMA EMPRESA RODOFERROVIÁRIA
}

\author{
Marcelo Klippel \\ José Antonio Valle Antunes Júnior \\ Ely Laureano Paiva
}

Programa de Pós Graduação em Administração, PPGA, Unidade Acadêmica de Pesquisa e Pós-Graduação, Universidade do Vale do Rio dos Sinos, UNISINOS, Av. Unisinos, 950, Bairro Cristo Rei, CEP 93022-000, São Leopoldo, RS, Brasil, e-mail: marcelo@klippel.com.br, junico@produttare.com.br, elpaiva@unisinos.br

Resumo

O mercado brasileiro apresenta características de intensa competição em certos segmentos industriais e escalas de produção globais reduzidas em comparação com os Estados Unidos, Europa e Japão. Certas empresas líderes em seus respectivos mercados, incluindo a situação da indústria rodoferroviária, necessitam desenvolver estratégias de negócio e de produção que tenham capacidade de atender a um ambiente competitivo caracterizado por: i) fabricar uma ampla faixa de produtos, procurando garantir um volume total de produção expressivo; ii) competir em mercados distintos, do ponto de vista das linhas de produtos fabricados; e iii) em muitos casos, enfrentar concorrentes menores focados na produção de linhas específicas. Assim, o presente artigo busca estudar e analisar as questões associadas à estratégia de produção de empresas com linhas de produtos diferenciadas. O referencial teórico apresenta conceitos acerca da estratégia de produção, partindo-se do método proposto por Hayes et al. (2005) para analisar a Estratégia Corporativa de Produção. Visando enriquecer os conceitos propostos por Hayes et al. (2005), propõe-se considerar a noção de Rede de Valor de Operações (RVO), em substituição às categorias de decisão clássicas, e o conceito de competências centrais. Após a construção do referencial teórico, é apresentado e discutido criticamente o caso de três linhas de produtos diferenciados da Randon Implementos. O trabalho desperta para a necessidade de se aprofundar a análise acerca das questões associadas à(s) estratégia(s) de produção nas empresas que fabricam linhas de produtos diversificadas. Em se tratando de decisões estratégicas para as organizações, é necessário considerar a empresa como um todo e as linhas de produtos diferenciadas em particular. Isto se dá no sentido em que, partindo-se da constatação de que as linhas diferenciadas competem com características e aspectos mercadológicos diferenciados, parece não poder haver uma única estratégia de produção passível de ser adotada homogeneamente em todas as linhas de produtos. Neste sentido, é necessária uma análise conjunta, sistêmica, complementar e inter-relacionada entre os aspectos genéricos da RVO e das competências centrais da empresa e os aspectos específicos ligados a RVO e as competências das linhas específicas de produtos.

Palavras-chave: estratégia de produção, critérios competitivos, categorias de decisão.

\section{Introdução}

A estratégia da produção diz respeito ao estabelecimento de políticas e planos amplos para utilizar os recursos de uma empresa, visando uma melhor sustentação de sua estratégia competitiva a longo prazo. Segundo Chase et al. (2004), a estratégia da produção pode ser vista como parte de um processo de planejamento que coordena os objetivos operacionais com os mais amplos das organizações. As estratégias de produção são desenvolvidas levando em conta os chamados critérios competitivos que possibilitam uma melhor análise acerca do 
posicionamento dos produtos e bens, frente às exigências do mercado/clientes. Usualmente são utilizados quatro critérios competitivos básicos: custos, qualidade, entrega e flexibilidade.

Paiva et al. (2004) colocam que a empresa industrial, além de selecionar as dimensões com as quais pretende competir, precisa orientar suas decisões e ações de forma coerente, buscando transformá-las em uma fonte de vantagem competitiva na(s) dimensão(ões) selecionada(s). Com o objetivo de facilitar o entendimento, essas decisões foram classificadas em categorias intituladas $\mathrm{Ca}$ tegorias de Decisão. Hayes et al. (2005) relacionam as categorias de decisão para a estratégia de produção da seguinte forma: capacidade, integração vertical e relação com fornecedores, instalações, informação e processos tecnológicos, alocação de recursos e sistemas de orçamento/capital, recursos humanos, sistemas de controle e planejamento do trabalho, sistemas da qualidade, sistemas de indicadores, sistemas de desenvolvimento de produto, processos e organização.

O trabalho foi desenvolvido na empresa Randon Implementos, uma empresa do Grupo Randon. O trabalho busca analisar a seguinte questão: "Como as características genéricas da empresa como um todo e específicas por linha de produto ou unidade de negócios contribuem para a definição da(s) estratégia(s) de produção da Randon Implementos, considerando-se uma análise em três linhas de produtos diferenciadas da empresa?"

\section{Referencial teórico}

A seguir são apresentados os principais conceitos associados à construção do modelo proposto neste trabalho. Basicamente, são tratados os aspectos relacionados com: cadeia de valor e rede de valor de operações, estratégia corporativa de produção, competências centrais e a abordagem proposta da estratégia corporativa de produção baseada na RVO.

\subsection{A rede de valor de operações}

Porter (1980) classifica as atividades de valor em duas categorias: i) Atividades primárias: logística de suprimento, operações, logística de distribuição, marketing e vendas, assistência técnica; e ii) Atividades de apoio: infra-estrutura de empresa, gerenciamento de recursos humanos, desenvolvimento de tecnologia, aquisição de insumos e serviços. As atividades podem ser representadas por uma cadeia genérica de valor.

Segundo Paiva et al. (2004), a cadeia de valor de Porter pode ser reinterpretada para a área de produção gerando uma Rede de Valor de Operações (RVO), composta das seguintes atividades: i) Desenvolvimento de Produto; ii) Suprimentos; iii) Produção; iv) Distribuição; e v) Serviços Agregados. A RVO busca compreender aspectos da cadeia de valor e das categorias de decisão, de forma a integrar sistemicamente todas as contribuições disponíveis para se expandir o conceito de valor ao longo da cadeia produtiva. Neste contexto, a área de produção é considerada como elemento central na integração da rede como um todo. A idéia da RVO consiste em apresentar as áreas da Cadeia de Valor de maneira sistêmica e integrada, buscando evidenciar que estas interagem entre si, eliminando a percepção seqüencial e integrando a área de Desenvolvimento de Produto, ausente no modelo de Cadeia de Valor. Além disso, a RVO recebe influência e pressão da concorrência e deve considerar as exigências do mercado.

Em se tratando de Unidade Estratégica de Negócios ( $S B U$ - Strategic Business Unit), cada SBU tem uma RVO específica, podendo ser diferenciada em qualquer atividade da RVO. A estratégia de negócios de uma $S B U$ tem que considerar a RVO em que está inserida. Assim, pode-se observar que é ainda mais relevante a necessidade de se definir e tratar a estratégia de negócios específica para o contexto de cada $S B U$. Os critérios competitivos são definidos a partir da RVO e das exigências de mercado, exercendo a tarefa de fornecer o foco estratégico a todos os elos das atividades. Quando da identificação e definição dos critérios competitivos, é necessário integrar as áreas, para que o entendimento e as escolhas estratégicas da empresa possam ser compatibilizados com os recursos operacionais disponíveis para dar suporte à estratégia competitiva (Hayes e Pisano, 1996). A escolha e posterior ênfase dos critérios competitivos a serem adotadas na $S B U$ ou empresa servirão para nortear as decisões e ações que deverão ser tomadas ou priorizadas ao longo da RVO. Se para cada $S B U$ tem-se uma RVO distinta e para cada RVO tem-se critérios competitivos identificados de maneira específica, as estratégias de negócios e de produção precisam levar em consideração a RVO e os critérios competitivos específicos de cada unidade. Assim, a RVO e os critérios competitivos são distintos para cada $S B U$ e as estratégias de negócios e produção podem ser diferentes para cada $S B U$.

Para Paiva et al. (2004), a busca por objetivos comuns em cada categoria, define a chamada coerência interna da estratégia de produção. A classificação das categorias não fornece indicações de como alcançar a coerência interna na estratégia de produção. Para tanto, busca-se analisar estas de forma agrupada no conceito das atividades inter-relacionadas na RVO.

\subsection{A estratégia corporativa de produção}

Hayes et al. (2005) propugnam a necessidade de compreender a Estratégia Corporativa de Produção em uma empresa com vários negócios. Os autores consideram duas definições para a estratégia corporativa de produção e as implicações de cada uma. A primeira definição para a estratégia corporativa de produção assume que esta existe somente ao ponto em que cada $S B U$ adota as mes- 
mas (ou muito similares) estratégias de produção. Entretanto, algumas reflexões sugerem que tal definição não é muito útil. Como cada $S B U$ tem aspectos particulares e, desta forma, uma estratégia de negócios específica, uma estratégia de produção comum pode não ser apropriada. Hayes et al. (2005) afirmam que mesmo para empresas nas quais diversos negócios empregam estratégias de negócios semelhantes, normalmente estes negócios apresentam diferenças suficientes, de modo que podem necessitar de estratégias de produção diferentes. Assim, acredita-se que a segunda definição para a estratégia corporativa de produção é mais útil do que a primeira. Esta segunda definição está baseada na existência de atributos e aspectos comuns entre os elementos estruturais e infra-estruturais das diferentes SBUs. Com a finalidade de explorar esta segunda idéia para a estratégia corporativa de produção, a Figura 1 explicita o desenvolvimento do conceito em cena.

Percorrendo as diversas categorias de decisão, é possível identificar algumas políticas sobre certos tipos de decisões que são comuns ao longo dos negócios. Estas políticas e atributos comuns são resultantes de um conjunto de valores comuns da empresa. Os aspectos de cada categoria de decisão são governados por políticas comuns para todas as $S B U s$. A área de Finanças, por exemplo, costuma adotar uma perspectiva de cunho corporativa.

É necessário identificar quais pontos de cada categoria de decisão são específicos por $S B U$ em particular e as questões comuns para todas as $S B U s$ em conjunto, ou seja, políticas, procedimentos, aspectos corporativos. Assim, é possível traçar estratégias de produção e de negócios específicas por $S B U$, coerentes com a estratégia de negócio da empresa como um todo e com a estratégia corporativa do grupo empresarial.

A discussão acerca da Estratégia Corporativa de Produção ainda deveria incorporar outras questões, visando enriquecer e completar a funcionalidade em termos de abrangência e efetividade quando da análise das estratégias de produção dentro da Organização. No item seguinte, apresenta-se o conceito de competências centrais, como forma de facilitar a compreensão da RVO como um todo.

\subsection{As competências centrais}

A partir dos anos 90, principalmente com a publicação do livro "Competing for the future" (Hamel e Prahalad, 1994), outros aspectos começaram a ser considerados quando da análise e tomada de decisões no campo estratégico. Paiva et al. (2004) apresentam o conceito de competências da empresa como "As competências da empresa são aquelas perceptíveis aos clientes e construídas a partir da combinação das competências de operações geradas a partir do uso criativo e inovador de seus diferentes recursos" (Paiva et al., 2004, p. 76).

As competências da empresa são habilidades e características que podem ser identificadas pelo mercado e muitas vezes, vinculadas diretamente à empresa que as detêm. Hamel e Prahalad (1994) definem três características necessárias para que uma competência seja considerada central: i) Valor para o cliente: deve proporcionar uma contribuição "desproporcional" para o valor percebido pelo cliente; ii) Diferenciação sobre concorrência: deve ser competitivamente única ou exclusiva, ou seja, uma competência que seja dominada por todo segmento industrial não deve ser considerada central; e iii) Extendabilidade: deve ter papel importante na abertura de novos mercados e oportunidades no futuro. Conforme Davis et al. (2001) e Corrêa e Corrêa (2004), a fim de implementar uma estratégia de produção com sucesso, algumas competências centrais devem ser identificadas. As competências centrais permitem à empresa estabelecer suas prioridades competitivas no mercado de trabalho.

Evidentemente, não devem ser identificadas as competências centrais apenas na função produção, também nas outras áreas funcionais é necessário definir e identificar as competências centrais. Assim, todas as competências funcionais deveriam convergir para um mesmo ponto estratégico, buscando atingir os objetivos da empresa, ou unidade de negócios.

Os autores destacam que a afirmação fundamental sobre esta nova visão emergente da estratégia competitiva - Visão Baseada em Recursos (VBR) - consiste no fato de que as empresas são bem sucedidas a longo prazo,

\begin{tabular}{|l|l|l|l|l|}
\hline \multicolumn{1}{|c|}{$\begin{array}{c}\text { Decisões da Estratégia de } \\
\text { Produção }\end{array}$} & \multicolumn{2}{c|}{$\begin{array}{c}\text { Estratégias de Negócios Individuais } \\
\text { Pegócíticas/Diretrizes Genéricas } \\
\text { (Corporação) }\end{array}$} \\
\hline Capacidade & & & & \\
\hline Instalações & & & & \\
\hline Tecnologia & & & & \\
\hline Integração Vertical & & & & \\
\hline Mão-de-obra & & & & \\
\hline Qualidade & & & & \\
\hline $\begin{array}{l}\text { Planejamento de Produção/ } \\
\text { Controle de Materiais }\end{array}$ & & & & \\
\hline Organização & & & & \\
\hline
\end{tabular}

Figura 1. O conceito da estratégia corporativa de produção. Fonte: adaptado de Hayes et al. (2005, p.73). 
não por construir e defender uma fortaleza competitiva, mas por serem capazes de fazer certas coisas melhor do que a concorrência. Muitas habilidades apenas podem ser desenvolvidas a longo prazo, com a experiência adquirida ao passar dos anos. Desta forma, além da definição das competências da empresa e de produção, é necessário definir alguns outros pontos importantes neste tema, basicamente os recursos e as atividades.

Para Paiva et al. (2004), os recursos podem ser entendidos como os ativos, informações e conhecimento controlados por uma empresa que a tornam capaz de conceber e implementar estratégias que melhorem sua competitividade. Em se tratando da RVO, pode-se entender como recursos todos os processos, equipamentos e pessoas com alguma relação com a produção e que considerados de maneira isolada não conduzem ao desempenho desejado. A partir desta afirmação, pode-se concluir que são as atividades que criam competências dentro da RVO. Os recursos por si só são apenas pontos estáticos, necessitando ser considerados em conjunto e integrados com a RVO.

\subsection{Estratégia corporativa de produção baseada na RVO}

O objetivo desta seção específica consiste em relacionar a Estratégia Corporativa de Produção de uma forma mais completa, buscando inserir elementos importantes para compor o Método de Análise de Estratégias de Produção. Para tanto, será discutida a Estratégia Corporativa de Produção sob o contexto da RVO, inserindo ainda as competências centrais como forma de facilitar a compreensão da RVO como um todo. A partir de então, retornase à Figura 2 buscando adaptá-la de forma a representar a Estratégia Corporativa de Produção na RVO de maneira mais sistêmica e completa.

Conforme observado na Figura 2, foram realizadas adaptações no modelo proposto por Hayes et al. (2005). Basicamente, buscou-se ampliar o modelo de Hayes et al. (2005) de forma a torná-lo mais completo e efetivo, pela integração com a RVO. O ambiente externo (mercado) exerce influência por meio da pressão da concorrência e das exigências dos clientes em termos de produtos e serviços. A partir deste ponto é possível identificar os critérios competitivos para cada uma das unidades ou negócios da empresa, levando-se em consideração tanto os aspectos externos (concorrência e exigências) quanto as particularidades de cada linha, unidade, negócio da empresa.

O ponto fundamental do modelo consiste na identificação e definição das políticas e diretrizes que dizem respeito à empresa como um todo e àquelas que são específicas para cada unidade de negócios. Assim, um conjunto de aspectos e decisões deve ser considerado tendo-se como unidade de análise o negócio/produto/linha, devendo gerar contribuições específicas para cada situação. Outro conjunto representa as questões genéricas para toda a corporação, devendo ser comum para todas as unidades de negócios da empresa. Neste ponto, pode-se observar que as ações genéricas para todas as unidades deverão gerar estratégias comuns para a empresa como um todo, enquanto que outro ponto consiste na definição de estratégias individuais, considerando-se as características e particularidades de cada unidade de negócios. Esta situação pode ser percebida a partir da dialética entre as partes e o todo. Esta dialética ainda deve ser enriquecida com uma análise específica para cada atividade da Rede de Valor de Operações, considerando-se, também, as categorias de decisão agrupadas por atividades. Ou seja, as políticas e diretrizes genéricas e específicas devem ser analisadas por atividade na RVO, objetivando avaliar e compreender as categorias de decisão para cada unidade de negócios em particular. Desta forma, busca-se avançar do modelo tradicionalmente utilizado, para um novo modelo que considera estas categorias dentro do escopo da RVO.

Por fim, devem-se considerar as competências centrais de cada unidade de negócios. As competências centrais têm por objetivo facilitar a compreensão dos pontos e cri-

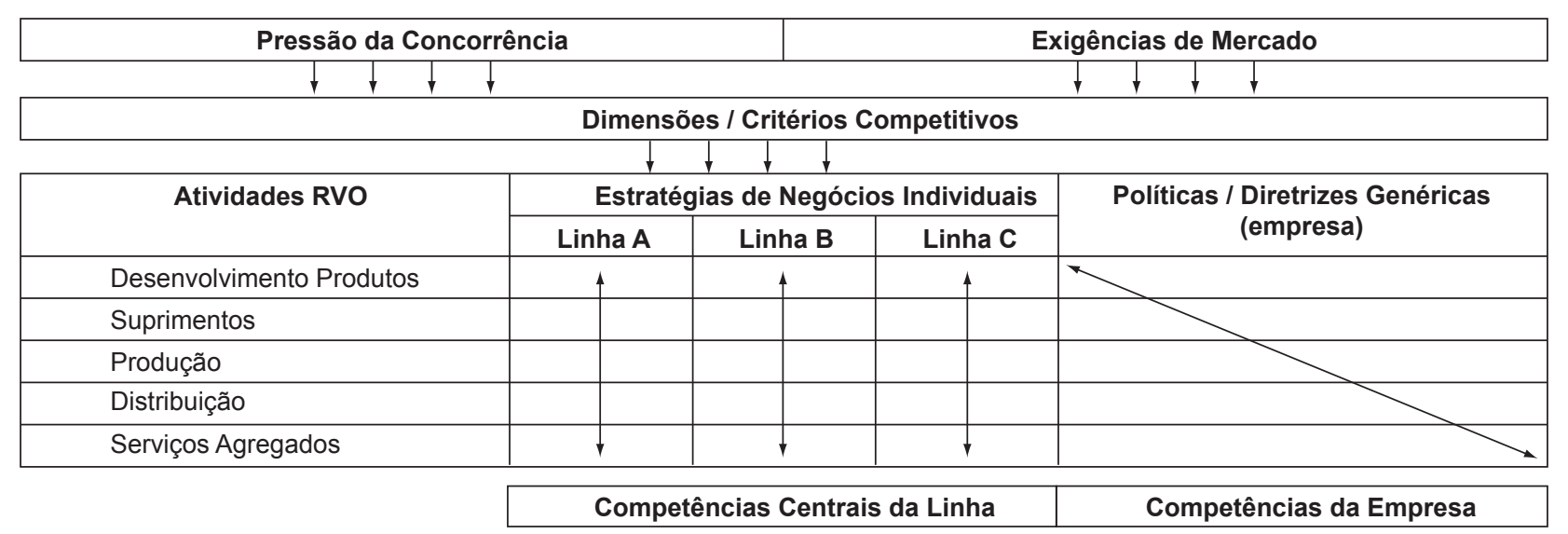

Figura 2. Estratégia Corporativa de Produção na RVO. Fonte: autores. 
térios relevantes para cada unidade de negócios. Devemse levar em consideração todas as atividades da RVO para se definir as competências centrais de cada unidade de negócios, pois, desta forma, a análise individual é enriquecida com mais elementos competitivos, contribuindo para a definição das estratégias de produção das SBUs em particular e da empresas como um todo. Além disso, existem também as competências centrais da Corporação, devendo ser tratadas como genéricas para a empresa como um todo.

\section{Método de trabalho}

\subsection{Método de pesquisa}

Yin (2001) coloca que o Estudo de Caso é a estratégia escolhida ao se examinarem acontecimentos contemporâneos, porém quando não se podem manipular comportamentos relevantes. O Estudo de Caso conta com técnicas utilizadas pelas pesquisas históricas, acrescentando duas fontes de evidências que usualmente não são incluídas no repertório de um historiador: observação direta e série sistemática de entrevistas. Segundo Roesch (1999), as características do Estudo de Caso são: a) estuda fenômenos em profundidade dentro de seu contexto; b) é especialmente adequado ao estudo de processos organizacionais; e c) explora fenômenos com base em vários ângulos. $\mathrm{O}$ Método de Pesquisa adotado é o Estudo de Caso Único com Objetos Incorporados na medida em que serão tratadas três linhas de produtos distintas da empresa, a partir de uma perspectiva de um único Estudo de Caso.

Buscando-se analisar os aspectos relacionados com os procedimentos de pesquisa e a sua operacionalização, optou-se por utilizar as fontes de evidências propostas por Yin (2001). Com relação à forma de coleta de dados por estas fontes de evidências, Yin (2001) salienta que três princípios são importantes para se obter benefícios destas fontes: Princípio 1: utilizar várias fontes de evidência; Princípio 2: criar um banco de dados para o estudo de caso; e Princípio 3: manter o encadeamento de evidências.

\subsection{Método de trabalho}

O Método de Trabalho utilizado é constituído por 6 passos apresentados a seguir.

O Passo 1 consistiu na escolha da empresa foco do Estudo de Caso. A Empresa foi selecionada por fabricar uma ampla gama de produtos para o mesmo segmento industrial. O Passo 2 consistiu na elaboração do referencial teórico. Para isso foi realizada uma pesquisa bibliográfica com o intuito de gerar uma abordagem teórica adaptada às necessidades da pesquisa. O Passo 3 compreendeu a delimitação do trabalho prático. Esta etapa é de suma importância na medida em que se manteve uma constan- te preocupação com o "enquadramento" da pesquisa à luz da teoria proposta. Com o andamento do trabalho, foi necessário complementar a teoria proposta e adequar os propósitos teóricos envolvidos.

O Passo 4 consistiu na construção do método de elaboração da pesquisa, utilizando-se para tal as fontes de evidência e os princípios para se obter benefícios destas fontes. A primeira fonte de evidência adotada foi a documentação proveniente das diversas áreas envolvidas com a pesquisa (exemplos: relatórios técnicos e gerenciais das áreas, gráficos de acompanhamentos, anotações diversas). Foi acessado um amplo conjunto de arquivos internos da Randon Implementos, sendo que nem todas as informações puderam ser transcritas para a presente pesquisa devido ao seu caráter sigiloso. Também foram utilizadas Entrevistas semi-estruturadas do tipo focal como fontes de evidências. Foi utilizado um conjunto de questões gerais com o objetivo de nortear a condução das entrevistas. A Observação Direta também foi utilizada como fonte de evidência. Neste ponto, salientam-se duas grandes atividades desenvolvidas ao longo do trabalho: i) diagnóstico; e ii) visitas in-loco. O Passo 5 consistiu no tratamento dos dados coletados por meio da transcrição das entrevistas realizadas em mídia eletrônica. Por fim, o Passo 6 consistiu na redação deste trabalho.

\section{Estudo de caso}

\subsection{Caracterização da empresa}

Conforme mencionado, a Randon Implementos é uma das empresas da Holding Randon Participações. A Holding tem como responsabilidade a definição do planejamento estratégico do conglomerado. A Randon Implementos projeta e desenvolve soluções para transporte. A linha de produtos fabricados engloba diferentes tipos de equipamentos, entre os quais: carrocerias, reboques, semi-reboques para o transporte de cargas secas, líquidas, indivisíveis e frigorificadas, sistema bimodal e silos. A empresa conta com mais de 200 mil produtos em operação nos diversos mercados mundiais. Segundo a empresa, de cada dez carretas que rodam pelas estradas brasileiras, cinco levam a marca Randon. A Empresa é líder no mercado nacional em seu segmento e o maior fabricante de implementos para o transporte da América Latina. O trabalho foi desenvolvido na matriz da Empresa em Caxias do Sul. Atualmente, os produtos são comercializados em mais de 50 países. A América Latina constitui o mercado mais representativo, seguida pela África e Europa.

A lógica de competição de cada uma das famílias de produtos é diferenciada, na medida em que a concorrência da Empresa é consideravelmente segmentada. Em termos de concorrência, a Empresa tem poucos concorrentes considerados de "primeira linha". Destas empresas, 
apenas uma - situada em São Paulo - parece tender a seguir o caminho de diversificação proposto estrategicamente pela Randon Implementos. Os concorrentes mais diretos da Randon são: Guerra, Facchin e Noma. Além destes, surgem alguns concorrentes intermediários, com pouca participação no mercado: Schiffer, Pastre, Rossetti e Antonini. Existem ainda cerca de outros 45 fabricantes menores, focados em poucas linhas de produtos.

Outro ponto importante refere-se ao fato de que este mercado tem variado muito ao longo dos anos. Nos períodos em que o mercado está em 'alta', existe uma tendência para a aquisição de produtos mais padronizados. Nos períodos recessivos da economia, cai substancialmente a busca pelos produtos mais padronizados e a Empresa responde ao mercado pela entrega de um número proporcionalmente maior de produtos especialmente projetados para a necessidade dos clientes. Em ordens de grandeza, o volume global de vendas anual deste mercado no Brasil é de cerca de 39.000 unidades em 2004. Para que se possa ter um parâmetro de referência, o mercado americano demanda em torno de 300.000 unidades e o mercado Europeu, em torno de 100.000 unidades. O primeiro ponto a ser considerado em termos da estratégia de produção é a baixa escala de produção das empresas que operam no mercado nacional, com relação aos fabricantes no exterior. Pode-se constatar que parecem existir dois pólos distintos e inter-relacionados de comportamento do mercado. A grande flexibilidade em termos do atendimento de uma vasta gama de famílias de produtos, acompanhada de uma substantiva variação do mix de produtos ao longo do tempo e uma escala global da indústria pequena, se constituiu, historicamente, em um elemento competitivo essencial para que a Empresa tenha se tornado líder de seu segmento de atuação no mercado. É relevante constatar que existem variações na lógica de demanda do mercado, inclusive nos produtos de maior consumo da Empresa.

\subsection{A empresa e as linhas de produtos}

As três linhas de produtos selecionadas para estudo e análise no presente trabalho e suas principais características são: i) Carga Seca/Graneleiro (CS/GR): produtos mais padronizados, volumes de produção elevados em relação aos demais produtos da Randon, pequenas quantidades em cada pedido, principal "carro-chefe"; ii) Tanques de Aço Carbono (TQ CO): intensificação do volume de trabalho da engenharia de produto/processo, mão-de-obra especializada, produto com alto valor agregado, produto caracterizado por uma necessidade contínua de inovação; e iii) Vagões Ferroviários: produto padronizado, grandes quantidades por pedido, poucos clientes e muito específicos, produto estratégico para o futuro da Empresa, lógica de gestão/estrutura organizacional distintas das demais linhas da Empresa.
Com a finalidade de apresentar as principais questões e características associadas à Randon Implementos como um todo e as três linhas de produtos selecionadas, seguiu-se a proposta da abordagem baseada na RVO. Assim, a Tabela 1 busca apresentar estas questões.

Além da segmentação envolvendo aspectos genéricos da Empresa e específicos das linhas de produtos, a Tabela 1 apresenta ainda alguns aspectos genéricos que englobam todas as atividades da RVO. Basicamente, é possível salientar algumas características específicas de cada linha de produto e a alocação dos setores administrativos e produtivos ao longo da cadeia de valor. Por exemplo, em se tratando dos setores de Marketing e Vendas, podese observar que são alocados para a Empresa como um todo, não apresentando atividades específicas para cada linha de produto. Em contrapartida, pode-se dizer que existe uma semifocalização na atividade de produção da RVO das três linhas de produtos. Esta focalização em termos da atividade de produção não é completa, uma vez que apenas as linhas de montagem e montagem final são contempladas em cada RVO específica. Já os setores de Caldeiraria e Pintura são genéricos para todas as linhas de produtos. A falta de focalização nos setores de Caldeiraria e Pintura gera conseqüências em diversos pontos da $\mathrm{RVO}$, principalmente no que tange às questões associadas ao PCP. Outro exemplo relevante consiste na atividade de distribuição, uma vez que, com exceção da linha de vagões ferroviários, para todas as demais linhas, os produtos finais são entregues ao cliente no próprio pátio da Empresa, passando-se então a responsabilidade para os clientes. Conforme pode ser observado, para o caso dos vagões ferroviários, o produto é entregue diretamente no cliente, permanecendo sob responsabilidade da Empresa até a concretização da entrega.

É possível observar que existe uma tendência de focalização das linhas de produtos, em se tratando das atividades de produção. Porém, parece não existir indícios que esta focalização na fábrica deve avançar para o conceito de $S B U s$. Como mencionado, para se tornar uma $S B U$, as linhas de produtos deveriam contemplar mais amplamente as outras atividades da RVO, ou seja: aspectos mercadológicos, desenvolvimento de produtos, suprimentos, distribuição e serviços agregados. Neste momento, cabe ressaltar a necessidade da separação entre aspectos práticos e da estrutura organizacional. Na prática, é possível que existam recursos dedicados para uma determinada linha de produtos, mesmo que organizacionalmente estes recursos estejam alocados em outro setor. Por exemplo, para o caso do desenvolvimento de produtos, a linha CS/GR possui engenheiros dedicados para os produtos desta linha. Porém, estruturalmente, eles não estão alocados sob responsabilidade do negócio CS/GR. Da mesma forma, para a grande maioria dos produtos, os serviços 
Tabela 1. Aspectos Genéricos e Específicos da RVO Empresa e RVOs Linhas de Produtos.

\begin{tabular}{|c|c|c|c|c|}
\hline \multirow{2}{*}{$\begin{array}{c}\text { Atividades da } \\
\text { RVO }\end{array}$} & \multicolumn{3}{|c|}{ Aspectos Específicos da Linha } & \multirow{2}{*}{$\begin{array}{c}\text { Aspectos Genéri- } \\
\text { cos da Empresa } \\
\end{array}$} \\
\hline & CS/GR & TQ CO & Vagão Ferroviário & \\
\hline Aspectos Mercado & $\begin{array}{l}\text { - Volume de produção } \\
\text { nacional crescente; } \\
\text { - Participação crescente no } \\
\text { mercado; } \\
\text { - Principal produto em } \\
\text { termos de volume de pro- } \\
\text { dução/participação; e } \\
\text { - Perdendo market-share. }\end{array}$ & $\begin{array}{l}\text { - Volume de produção na- } \\
\text { cional com pequena taxa } \\
\text { de crescimento; } \\
\text { - Participação decrescente } \\
\text { no mercado; e } \\
\text { - Conquista de market- } \\
\text { share. }\end{array}$ & $\begin{array}{l}\text { - Volume de produção } \\
\text { nacional crescente; } \\
\text { - Demanda centralizada em } \\
\text { poucos clientes; } \\
\text { - Pouco volume de produ- } \\
\text { ção em relação aos demais } \\
\text { produtos; e } \\
\text { - Conquista de market-share. }\end{array}$ & $\begin{array}{l}\text { - Alto custo com frete } \\
\text { de transporte; } \\
\text { - Setor de Marketing } \\
\text { (exceto Vagões); e } \\
\text { - Setor de Vendas } \\
\text { (exceto Vagões). }\end{array}$ \\
\hline $\begin{array}{l}\text { Desenvolvimento } \\
\text { de Produtos }\end{array}$ & $\begin{array}{l}\text { - Itens em CKDs (kits de } \\
\text { conjuntos de peças para } \\
\text { montagem no cliente); e } \\
\text { - Engenharia de Produto } \\
\text { focada. }\end{array}$ & $\begin{array}{l}\text { - Busca por maior qualidade } \\
\text { de produtos; } \\
\text { - Itens de segurança; } \\
\text { - Itens em CKDs; e } \\
\text { - Engenharia de Produto } \\
\text { focada. }\end{array}$ & $\begin{array}{l}\text { - Itens de segurança; } \\
\text { - Necessidade de desenvol- } \\
\text { ver os truques interna- } \\
\text { mente; e } \\
\text { - Engenharia de Produto } \\
\text { dedicada. }\end{array}$ & $\begin{array}{l}\text { - Inovação é um dos } \\
\text { critérios relevantes } \\
\text { para melhorar todas } \\
\text { as linhas. }\end{array}$ \\
\hline Suprimentos & $\begin{array}{l}\text { - Kanban Interno (Almoxa- } \\
\text { rifado e Linha); e } \\
\text { - Custo de matéria-prima é } \\
\text { muito elevado (primeiro } \\
\text { dos 3). }\end{array}$ & $\begin{array}{l}\text { - Custo de matéria-prima é } \\
\text { muito elevado (segundo } \\
\text { dos } 3 \text { ). }\end{array}$ & $\begin{array}{l}\text { - Matéria-prima específica; } \\
\text { - Fornecedores específicos; e } \\
\text { - Custo de matéria-prima } \\
\text { é muito elevado (terceiro } \\
\text { dos 3). }\end{array}$ & $\begin{array}{l}\text { - Compras MRP; } \\
\text { - Produção MRP; } \\
\text { - Suprimentos; } \\
\text { - Setor Compras (ex- } \\
\text { ceto Vagões); e } \\
\text { - Setor Desenv. For- } \\
\text { necedores. }\end{array}$ \\
\hline Produção & $\begin{array}{l}\text { - Supervisão; } \\
\text { - Mão-de-obra (M.O.) } \\
\text { direta; } \\
\text { - Capacidade < Demanda; } \\
\text { - Itens para CKDs; } \\
\text { - Nível elevado de entregas } \\
\text { no prazo; e } \\
\text { - Semi-Focalização } \\
\end{array}$ & $\begin{array}{l}\text { - Supervisão; } \\
\text { - Mão-de-obra direta; } \\
\text { - Capacidade < Demanda; } \\
\text { - MO especializada ; } \\
\text { - Itens para CKDs; } \\
\text { - Semi-Focalização; e } \\
\text { - Alguns recursos da Caldei- } \\
\text { raria dedicados. }\end{array}$ & $\begin{array}{l}\text { - Supervisão; } \\
\text { - Mão-de-obra direta; } \\
\text { - Capacidade > Demanda; e } \\
\text { - Fábrica Semi-Focalizada. }\end{array}$ & $\begin{array}{l}\text { - Eficiência MO; } \\
\text { - Diretoria e Gerência } \\
\text { de Operações; } \\
\text { - Caldeiraria; } \\
\text { - Pintura; } \\
\text { - Ferramentaria; } \\
\text { - Manutenção; e } \\
\text { - RH. }\end{array}$ \\
\hline Distribuição & $\begin{array}{l}\text { - Entrega na expedição; } \\
\text { - Respons. do Cliente; e } \\
\text { - Venda direta apenas na } \\
\text { Randon (fábrica). }\end{array}$ & $\begin{array}{l}\text { - Entrega na expedição; } \\
\text { - Respons. do Cliente; e } \\
\text { - Venda direta apenas na } \\
\text { Randon (fábrica). }\end{array}$ & $\begin{array}{l}\text { - Entrega no Cliente; } \\
\text { - esponsabilidade da Ran- } \\
\text { don; e } \\
\text { - Venda direta no Cliente } \\
\text { (projetos). }\end{array}$ & $\begin{array}{l}\text { - Setor de Expedição } \\
\text { (exceto Vagões). }\end{array}$ \\
\hline $\begin{array}{l}\text { Serviços } \\
\text { Agregados }\end{array}$ & $\begin{array}{l}\text { - Peças de reposição sob } \\
\text { responsabilidade do setor } \\
\text { Pós-Venda; } \\
\text { - Serviços de pós-venda sob } \\
\text { responsabilidade do setor } \\
\text { Pós-Venda. }\end{array}$ & $\begin{array}{l}\text { - Peças de reposição sob } \\
\text { responsabilidade do setor } \\
\text { Pós-Venda; } \\
\text { - Serviços pós-venda sob } \\
\text { responsabilidade do setor } \\
\text { de Pós-Venda. }\end{array}$ & $\begin{array}{l}\text { - Peças de reposição sob } \\
\text { responsabilidade da } \\
\text { Engenharia e Produção do } \\
\text { setor; e } \\
\text { - Serviços pós-venda sob } \\
\text { responsabilidade da Enge- } \\
\text { nharia do setor. }\end{array}$ & $\begin{array}{l}\text { - Setor de Pós-Venda } \\
\text { (exceto Vagões). }\end{array}$ \\
\hline
\end{tabular}

Fonte: Autores.

envolvidos estão sob responsabilidade de um setor em separado, porém possuindo recursos dedicados para as linhas de produtos. Para o caso dos Vagões, os serviços são de responsabilidade da própria linha, não estando estruturalmente organizados em um setor separado.

A linha de Vagões, conceitualmente, se assemelha a uma $S B U$, dado que diversas atividades da RVO estão contempladas na linha, tais como: desenvolvimento de produtos, suprimentos, distribuição e serviços agregados, além da semifocalização da fábrica, que se dá apenas no âmbito da linha de montagem e montagem final. Esta semifocalização permite um avanço em termos das linhas de montagem e montagem final, uma vez que possibilita uma maior agilidade e velocidade em termos de lead-time e no que tange a questões associadas com a diminuição da necessidade de trocas na linha. Porém, apesar deste avanço, a não-focalização em termos de Caldeiraria e, principalmente, do setor de Pintura, tende a levar a um aumento do lead-time dos produtos, enquanto uma consequiência das dificuldades associadas ao seqüenciamento e priorização das atividades (produtos) nos recursos da Pintura.

Parece importante pontuar que um encaminhamento processual no sentido da constituição das $S B U s$ em toda a Empresa é um caminho estratégico interessante a ser 
perseguido. $\mathrm{O}$ argumento central desta proposição consiste em perceber as diferenciações significativas em termos dos mercados de atuação da Empresa. Tratar a problemática a partir da noção de $S B U s$, formal ou informalmente, sugere a possibilidade de montar uma estrutura de gestão - envolvendo as diferentes funções e áreas Administrativas: Marketing, Vendas, Engenharia de Produto/Processo, Produção, Distribuição, Assistência Técnica - que possa construir, processualmente, uma visão mais sistêmica e estruturada dos trabalhos desenvolvidos com foco no atendimento das necessidades específicas dos diferentes mercados. Para isso, a análise das RVOs por $S B U$ pode ser um ponto de partida eficaz. No entanto, a constituição das $S B U s$ pode acarretar duas consequiências: i) uma perda da noção do 'todo' da Empresa; e ii) a subotimização dos recursos produtivos a partir de uma perspectiva econômica. Neste sentido, tal percepção no caminho da descentralização da gestão, não implica dizer que todas as atividades devam ser descentralizadas. Por exemplo, as decisões estratégicas relativas à marca, às finanças - incluindo a seleção geral dos investimentos na Empresa - e o setor de compras de grande volume, por sua característica sistêmica, relacionado ao poder da Empresa (exemplo: compra de aço) e totalizante, provavelmente necessitam de centralização. Ainda, no âmbito operacional, existem dificuldades técnicas objetivas que impedem, ou tornam ineficaz sob a ótica econômica, a descentralização dos recursos. Assim, um direcionamento processual para as $S B U s$ parece possível de ser realizado na Empresa, sem descaracterizar as vantagens derivadas da centralização - o que implica em realizar um conjunto de atividades, a serem parcimoniosamente consideradas, do prisma centralizado.

\subsection{Análise crítica à luz da estratégia de produção}

Partindo de uma perspectiva histórica, pode-se dizer que a Randon Implementos tende a tratar as competências centrais de maneira agregada. Historicamente, a competência central teve ênfase na Engenharia de Produto, dado que a Empresa sempre se destacou frente aos concorrentes nos aspectos ligados à atividade de Engenharia de Produtos. Pelo caráter de liderança de mercado, a Randon Implementos se caracterizava por inovar e lançar novos produtos, modelos e tecnologias. As empresas seguidoras buscam se adaptar e 'copiar' os produtos da Randon. Porém, a competência em Engenharia de Produto parece não representar mais um diferencial do mercado em todas as linhas de produtos da Empresa. Por exemplo, no caso da linha CS/GR, em 'grandes linhas', a Engenharia de Produto é razoavelmente dominada pelos principais fabricantes do segmento. De outro lado, no caso da linha TQ CO, os aspectos de inovação do produto representam um grande diferencial para a Empresa.
Também pode se definir como outra competência central para a Empresa a competência na produção, compreendida como Eficácia nas Operações. A utilização de modernas teorias e técnicas de gestão na produção tem possibilitado à Empresa obter melhorias no que tange à eficácia na produção. Por exemplo, a partir dos Processos de Capacitação Tecnológica atualmente desenvolvidos na Empresa e do conhecimento de seus profissionais, abordagens como o Sistema Toyota de Produção e a Teoria das Restrições são utilizadas e adotadas na produção como um todo. Atualmente, os conceitos e princípios destas abordagens são amplamente conhecidos e difundidos ao longo de todas as atividades da RVO da Empresa. Pelo caráter inovador e pela consistência observada nos programas de treinamento e nas aplicações e implementações dos projetos de melhorias constituídos, pode-se salientar que a Eficiência na Produção pode ser entendida como uma competência central da Empresa. Apesar de ainda se observarem grandes possibilidades de ganhos e melhorias no que tange à eficiência na produção, algumas linhas de produtos podem estar necessitando de um salto tecnológico maior e mais rápido, de modo que, no futuro, apenas a Eficiência na Produção pode não assegurar um diferencial frente aos concorrentes do setor.

Ainda, é possível identificar uma outra competência central da Empresa referente ao setor e às atividades que envolvem a Ferramentaria, o que pode ser evidenciado por três razões principais: i) habilidades da Ferramentaria em relação ao desenvolvimento dos produtos e processos para todas as linhas da Empresa; ii) ações fundamentais para a flexibilização das linhas de montagem/montagem final e da Caldeiraria; e iii) contribuição para o desenvolvimento de muito conhecimento interno intrínseco, uma vez que o know-how para fabricação dos produtos da Randon permanece sob domínio tecnológico da própria Empresa.

Assim sendo, podem-se analisar as competências centrais da Empresa a partir de dois aspectos gerais: a "validade" das competências centrais atualmente em questão e a necessidade de se tratarem as competências centrais de maneira específica - por linha de produtos. Basicamente, tanto as competências centrais, envolvendo a Engenharia de Produto, a Eficiência na Produção e a Ferramentaria, por si só, parecem não garantir, no futuro, o diferencial competitivo da Randon Implementos como um todo. As competências centrais da Empresa não só podem necessitar ser repensadas do ponto de vista agregado como também parece ser necessário iniciar uma análise mais focalizada, instituindo competências centrais específicas para as linhas de produtos. Esta necessidade pode ser observada, uma vez que os mercados em que os produtos da Randon competem são consideravelmente diferenciados, o que, provavelmente, venha a requerer a constru- 
ção de estratégias e competências distintas por linhas de produto.

Ainda é possível relacionar mais uma competência atualmente observada na Randon Implementos. Esta diz respeito à (competência) flexibilidade em atender competitivamente a toda faixa de produtos para implementos rodoviários. Esta competência é observada na medida em que apenas a Randon Implementos produz toda a linha de produtos do mercado nacional. Quando se considera o mercado externo, esta característica pode ser ressaltada, uma vez que os grandes fabricantes, no exterior, tendem a apresentar uma produção bem mais focalizada em apenas algumas linhas de produtos, quando não apenas em um produto específico. Neste sentido, a flexibilidade de atender a toda faixa de produtos do mercado de forma competitiva pode ser considerada uma competência central da Empresa. De forma geral, os fabricantes que concorrem com a Randon no mercado interno tendem a procurar posições competitivas associadas à obtenção de custos menores e preços mais competitivos, não apresentando flexibilidade para atender a todo mercado de carretas. Neste ponto pode ser observada a questão dos trade-offs.

Em termos de pontos de alavancagem para a Linha CS/ GR foram apontadas as atividades envolvendo a questão de suprimentos. Isto decorre do fato de que é elevado o percentual do custo de matéria-prima em relação ao preço de venda dos produtos. Sendo assim, todas as melhorias e benefícios relacionados com a redução do custo dos materiais exercem impacto direto no ganho individual do produto. As melhorias nos suprimentos podem fazer com que os produtos CS/GR possam, inclusive, apresentar uma diminuição no seu preço de venda e, desta forma, auxiliar na recuperação da participação no mercado.

$\mathrm{Na}$ Linha TQ CO, o ponto de alavancagem parece ser a inovação de produto. O setor de desenvolvimento de produto direciona esforços para o lançamento de produtos inovadores, como forma de manter o crescimento constante da participação de mercado. Além de se preocupar com o avanço em termos de design, os profissionais ligados ao desenvolvimento de produto precisam manter-se atualizados em termos dos itens de segurança dos produtos TQ CO. Esta situação sempre é crítica, na medida em que o principal produto transportado pelos TQ CO são líquidos inflamáveis. A Randon Implementos, como líder de mercado neste segmento, tem a responsabilidade intrínseca de inovar continuamente com seus produtos, visando manter elevada a participação neste mercado. Em se tratando das exportações dos produtos TQ CO, a Engenharia de Produto exerce um papel fundamental no que tange às adequações e alterações necessárias para atender às legislações dos países importadores, bem como às exigências diferenciadas de cada cliente externo.

Para o caso da Linha de Vagões Ferroviários, por se tratar de um produto muito recente na realidade da Ran- don, as possibilidades de melhorias podem ser visualizadas em praticamente todas as atividades da RVO desta linha. Um ponto de alavancagem importante consiste também na atividade de desenvolvimento de produtos. Como a linha em questão é recente, o produto em si ainda não está totalmente definido, uma vez que a Empresa vem se adequando continuamente conforme demanda do mercado. Assim, há uma necessidade pela busca da padronização dos componentes e itens adquiridos. Um componente que poderia trazer ganhos significativos consiste no desenvolvimento dos truques para os vagões ferroviários. Atualmente os componentes para os truques são adquiridos de fornecedores externos. Esta situação diminui a flexibilidade da Empresa frente às exigências de mercado, visto que o principal concorrente produz internamente todo o conjunto do vagão ferroviário, inclusive os truques. A situação ainda é agravada pelo fato de que existe uma grande dificuldade para fornecer para todos os clientes, visto que alguns só podem adquirir vagões com bitolas específicas, que atualmente ainda não são produzidos pela Randon. Uma alternativa consiste em buscar ou desenvolver fornecedores para todas as especificações de bitola. Porém, desta forma, ainda a tecnologia permanece com os fornecedores e a dependência da Empresa tende a persistir. Em termos da atividade de produção, mais especificamente com relação à capacidade produtiva, atualmente existe capacidade ociosa para aumentar o volume de produção, sendo que o principal ponto restritivo consiste nas atividades de vendas. Neste sentido, parece existir a necessidade de um trabalho forte em conjunto com as áreas de desenvolvimento de produtos e comercial, visando à conquista de novos pedidos e clientes.

Em termos de pontos a melhorar para a Linha CS/GR, as atividades envolvendo a produção são relevantes. Em se tratando da atividade de produção, pode se salientar que este é um ponto de centralidade uma vez que a capacidade é menor do que a demanda. Este ponto ainda parece ser possível de ser melhorado, uma vez que a Randon Implementos vem perdendo participação no mercado. Desta forma, é nitidamente necessário aumentar a capacidade de produção desta linha, de modo a atender ao mercado e reconquistar a participação percentual no mercado. Este aumento de capacidade deve ser acompanhado de uma maior flexibilidade no que tange à produção. Apesar do caráter mais padronizado da Linha CG/GR, os lotes de produtos por pedido são pequenos, havendo necessidade de se adequar constantemente o fluxo produtivo - a questão das preparações de linha (setups).

Em se tratando da Linha TQ CO, também as atividades envolvendo a produção poderiam ser alvo de atenção por parte dos profissionais da Empresa. Ao contrário da Linha CS/GR, a demanda total do mercado de TQ CO está diminuindo nos últimos anos. Em contrapartida, a parti- 
cipação da Randon está aumentando significativamente neste mesmo período. Ou seja, parece que as questões associados à competição se tornam cada vez mais relevantes, uma vez que uma menor quantidade de unidades está sendo colocada no mercado e os fabricantes precisam competir por um volume de produção pequeno. Assim, as questões associadas com capacidade produtiva e flexibilidade se tornam importantes para compor a estratégia de atendimento e conquista contínua do mercado. As ações relacionadas com a gestão do sistema produtivo, de maneira geral, e da capacidade produtiva, de forma particular, deveriam ser consideradas para permitir uma rápida resposta ao mercado, se isto se fizer necessário.

Com relação à Linha de Vagões Ferroviários, pode-se apontar a atividade de distribuição como um ponto possível de ser melhorado. A principal dificuldade consiste na inexistência de ferrovias ligando Caxias do Sul às demais cidades do Brasil. Este fato impossibilita a distribuição dos vagões ferroviários produzidos pela Randon, sem a necessidade de outro veículo para transportá-los. Nos demais concorrentes, existe uma linha férrea específica que passa literalmente dentro da Empresa, permitindo que os fabricantes liberem os vagões produzidos diretamente para os clientes. Os clientes buscam os vagões nos fabricantes e os conduzem "rodando" na linha férrea até o seu destino. Esta característica também exerce impacto direto na responsabilidade pela atividade de distribuição. No caso da Randon, a responsabilidade na entrega/transporte do produto ao cliente é da própria Empresa.

Considerando-se a RVO no âmbito da empresa, é possível salientar alguns pontos significativos no que tange à busca por uma maior agregação de valor na RVO frente aos resultados obtidos pela Empresa. Para as atividades envolvendo as questões mercadológicas, pode se salientar a necessidade de um constante acompanhamento no que diz respeito às condições de mercado, tanto nacional como no exterior. Por meio de pesquisas e dados oficiais pode-se manter o mercado sob constante observação, de modo a perceber potenciais oportunidades e riscos envolvidos no mercado. Desta forma, clientes, fornecedores, concorrentes, governos, precisam ser estudados de forma a trazer benefícios para a Empresa. Em se tratando das atividades de desenvolvimento de produto, como a Empresa apresenta uma característica de atender a uma ampla linha de produtos e de diversos modelos e especificações, as questões envolvendo esforços contínuos em direção à padronização são relevantes. Um ponto de discussão consiste na possibilidade de se trabalhar mais amplamente com o conceito de modularização (Starr, 1965), uma vez que, desta forma, a Empresa poderia atender mais rapidamente às exigências específicas de mercado e simultaneamente aos aspectos ligados à produção que apontam no sentido de uma maior padronização.
Um dos aspectos significativos, enquanto ponto passível de melhorias, relaciona-se com a atividade de suprimentos. Apesar da Linha CS/GR apresentar o maior percentual do custo de matéria-prima em relação aos demais produtos, as demais linhas também apresentam este panorama. Assim, as melhorias nesta atividade podem contribuir significativamente para o desempenho da Empresa como um todo. Em termos da atividade de produção para a RVO da Empresa, pode-se dizer que uma questão que possivelmente traria benefícios para a Empresa consiste em melhorar a gestão das restrições. Esta ação permitirá um avanço no sentido de melhorar a medição e acompanhamento da real capacidade fabril, buscando gerir de forma eficaz os recursos produtivos, considerando-se as limitações e restrições do sistema produtivo da Empresa. Atualmente, pela divisão da linha de montagem em boxes de operações, os trabalhos realizados no sentido de melhorar a eficiência da linha já buscam priorizar os recursos críticos. A partir da identificação do boxe restritivo, as ações de melhorias são direcionadas para estes recursos. Ainda, pode-se salientar que a complexidade envolvendo a atividade de PCP poderia ser minimizada com a utilização de modernas ferramentas para programação da produção. Assim, esta complexidade, agravada pelo compartilhamento de alguns recursos, poderia ser tratada e gerenciada com ferramentas de Programação Fina de Produção. Pelo caráter sistêmico desta ferramenta, um maior número de variáveis, cenários, produtos e recursos podem ser visualizados simultaneamente. Isto tende a permitir um gerenciamento amplo do conjunto de restrições do sistema produtivo. Esta forma de gerenciamento pode contribuir para aumentar a flexibilidade, uma vez que os recursos serão gerenciados mais eficazmente, podendo aumentar a capacidade da linha.

Para a atividade de distribuição, uma característica que parece ser crítica consiste na dificuldade em se transportar o produto fabricado pela Empresa. Com exceção da Linha de Vagões Ferroviários, o cliente busca o produto na própria Randon. Ainda, aumentando-se a exportação, principalmente a partir da adoção dos CKDs, deve-se repensar na melhor estratégia de distribuição para a Empresa, de modo a minimizar os custos envolvidos e atender às exigências do cliente da melhor maneira possível.

Analisando-se a RVO da Empresa do ponto de vista das atividades envolvendo serviços agregados, pode se observar que existem oportunidades relacionadas ao aumento da participação no mercado de peças de reposição, dado que grande parte das peças repostas no mercado não são peças originais Randon. Além disso, todo o serviço que possa ser melhorado ou adicionado para o cliente final é bem visto, na medida em que estes serviços podem ser entendidos como garantia de bons produtos e no bom atendimento ao consumidor. 


\section{Considerações finais}

Para o desenvolvimento do método de estratégia de produção utilizado nesta pesquisa, partiu-se do método proposto por Hayes et al. (2005). Porém, acredita-se que o método proposto por Hayes et al. (2005) não compreende completamente questões significativas no que diz respeito principalmente à RVO e às competências centrais da Empresa e das SBUs. Portanto, buscou-se adaptar o método proposto pelos autores, visando incorporar estas novas questões. Primeiramente, buscando representar a realidade da Empresa foco do Estudo de Caso, optou-se por trocar a denominação de "Estratégia Corporativa de Produção" para "Estratégia de Produção da Empresa" e as "Unidades Estratégicas de Negócios" para "Linha de Produtos". Isto foi necessário, uma vez que, para o caso da Randon Implementos, um outro trabalho a ser desenvolvido poderia considerar o Grupo e as empresas do Grupo. Para este trabalho, a unidade de análise é apenas uma empresa do Grupo - a Randon Implementos. Em um segundo momento, inseriu-se a noção de atividades da RVO em substituição ao conceito de categorias de decisão. Desta forma, todas as atividades poderiam ser analisadas a partir do ponto de vista das linhas de produtos específicas e da Empresa. Na seqüência, incorporou-se a análise das competências centrais genéricas da Empresa e das competências centrais específicas de cada linha de produto. Estas adaptações permitiram desenvolver a análise do Caso de forma mais consistente e completa do ponto de vista teórico.

Para o desenvolvimento do Estudo de Caso propriamente dito, partiu-se da teoria e do método de estratégia de produção propostos no referencial teórico. Em um primeiro momento buscou-se apresentar a Empresa como um todo, relacionando as principais questões genéricas para todas as linhas de produtos, bem como uma descrição das atividades da RVO Corporativa (Empresa). Em um segundo momento, além de apresentar os principais aspectos específicos relacionados com cada linha de produto em particular, seguiu-se também a descrição das atividades da RVO e da cadeia de valor sob a perspectiva específica de cada linha de produto. Em termos da Empresa como um todo é possível concluir que, historicamente, a Empresa tem tratado as questões associadas com a es- tratégia de produção de maneira agregada. Ainda, em se tratando das competências centrais, é possível afirmar que o foco sempre esteve voltado para a Empresa como um todo, não diferenciando as competências centrais específicas para as linhas de produtos. Resumidamente, as competências centrais sempre estiveram fortemente relacionadas, de maneira genérica, com as questões associadas à Engenharia de Produção, Eficiência na Produção e Ferramentaria. Em se tratando das linhas de produtos, puderam-se identificar alguns pontos de alavancagem possíveis de serem implementados e gerarem benefícios/ganhos significativos. Também foram identificados alguns pontos a melhorar em cada uma das três linhas analisadas na presente pesquisa.

As conclusões acerca da Relação entre o Método e o Estudo de Caso são: Pode-se salientar a necessidade de se realizar uma análise da estratégia de produção segundo dois focos distintos e complementares. O primeiro foco consiste na análise da estratégia de produção enquanto um aspecto genérico para toda a Empresa. Neste sentido, este primeiro ponto é importante, uma vez que existem questões e características que são comuns para a empresa como um todo e, desta forma, devem ser identificados a partir de uma perspectiva macro. O segundo foco, essencial para a compreensão estratégica da Empresa, consiste na análise da estratégia de produção, levando em consideração as características e especificidades de cada linha de produto em particular. A partir da constatação de que diferentes linhas de produtos podem competir de acordo com diferentes critérios competitivos e características de mercado, uma análise detalhada e focada na linha de produto é necessária para identificar, analisar e tratar as questões específicas no âmbito da linha de produto. Neste sentido, os dois focos de análise direcionam os esforços para compreender a Empresa como um todo, a partir de uma inter-relação permanente entre as partes - as unidades focalizadas/unidades de negócio - e o todo - a Empresa. O caminho para esta compreensão implica em realizar duas análises com focos distintos (empresa e linhas de produtos), porém complementares e inter-relacionados, no sentido em que é necessário considerá-las para que se torne possível analisar todos os aspectos envolvidos em termos da formulação e implantação da estratégia de produção.

\section{Referências Bibliográficas}

CHASE, R. B.; JACOBS, F. R.; AQUILANO, N. J. Operations Management for Competitive Advantage. $10 \mathrm{ed}$. New York: McGraw Hill, 2004. 800 p.

CORRÊA, L. H.; CORRÊA, C. A. Administração de Produção e Operações: Manufatura e Serviços - Uma abordagem Estratégica. São Paulo: Atlas, 2004. 694 p.
DAVIS, M. M.; AQUILANO, N. J.; CHASE, R. B. Fundamentos da Administração da Produção. 3 ed. Porto Alegre: Bookman, 2001. 600 p.

HAMEL, G.; PRAHALAD, C. K. Competing for the Future. USA: Harvard Business School Press, 1994. 360 p. 
HAYES, R.; et al. Pursuing the Competitive Edge. Danvers: John Wiley \& Sons, 2005. 360 p.

HAYES, R.; PISANO, G. Manufacturing Strategy: At the Intersection of Two Paradigm Shifts. Production and Operations Management, v. 5, n. 1, p. 25-41, Spring 1996.

PAIVA, E. L.; CARVALHO JR., J. M.; FENSTERSEIFER, J. E. Estratégia de Produção e de Operações: Conceitos, Melhores Práticas e Visão de Futuro. Porto Alegre: Bookman, 2004. 192 p.

PORTER, M. E. Estratégia competitiva: Técnicas para análise de indústrias e da concorrência. Rio de Janeiro:
Campus, 1980. $448 \mathrm{p}$.

ROESCH, S. M. A. Projetos de Estágios e de Pesquisa em Administração: Guia para Estágios, Trabalhos de Conclusão, Dissertações e Estudos de Caso. 2 ed. São Paulo: Atlas, 1999. 312 p.

STARR, M. K. Modular Production. A New Concept. Harvard Business Review, v. 43, p. 131-142, nov./dez. 1965.

YIN, R. K. Estudo de caso: planejamento e métodos. 2 ed. Porto Alegre: Bookman, 2001. 205 p.

\title{
PRODUCTION STRATEGY OF COMPANIES WITH DIFFERENTIATED PRODUCTS LINES - CASE STUDY OF A ROAD AND RAILWAY EQUIPMENT COMPANY
}

\begin{abstract}
The Brazilian market is intensely competitive in certain industrial segments but its scale of global production is small compared with that of the USA, Europe and Japan. Though leaders in their respective markets, several companies, including the manufacturers of road and railway equipment for freight transportation, must develop business and production strategies that can compete effectively in an environment characterized by: 1) the manufacture of a wide range of products aimed at ensuring large total production volumes; 2) competition in distinct markets from the standpoint of manufactured product lines; and 3) in many cases, competition from smaller competitors focusing on specific product lines. This paper reports on a study and analysis of issues relating to the production strategy of companies with diversified product lines. The theoretical reference presents concepts of production strategy, based on the method proposed by Hayes et al. (2005), to analyze the corporate production strategy. To enrich the concepts of Hayes et al. (2005), we consider not only the notion of Operation Value Networks (OVNs) instead of the classical decision categories but also the concept of core competencies. The notion of OVNs provides a systemic view of value flow that makes it easy to understand the company and the business unit and contributes to the formulation of the company production strategy. The concept of core competencies, in turn, favors the identification of the company's core points that provide greater added value for customers. Pursuant to the construction of the theoretical reference, a critical discussion is presented of the Randon case, followed by a critical analysis of our case study, discussing the core competencies of Randon Implementos and establishing the main leverages and points of improvement for selected product lines based on the analysis of the respective OVNs. This dissertation also highlights the need for in-depth analyses of issues relating to the production strategies of manufacturers of diversified product lines. With regard to strategic decisions, the company must be considered as a whole, while diversified product lines should be considered separately. Based on evidence that diversified lines compete with differentiated market aspects and characteristics, it is reasonable to assume that a single production strategy cannot be adopted homogeneously for all product lines. Therefore, an overall analysis is required that is systemic, complementary and unified, interrelating generic aspects of OVNs with the company's core competencies as a whole, and with specific aspects of the OVN and the competencies of specific product lines.
\end{abstract}

Keywords: production strategy, operation value networks, core competencies, decision categories. 